University of Wollongong

Research Online

Faculty of Law, Humanities and the Arts Papers (Archive)

Faculty of Arts, Social Sciences \& Humanities

$1-1-2013$

Intellectual entrepreneurs and the diffusion of ideas: two historical cases of knowledge flow

Xiaoying Qi

University of Western Sydney, xiaoying@uow.edu.au

Follow this and additional works at: https://ro.uow.edu.au/lhapapers

Part of the Arts and Humanities Commons, and the Law Commons

Research Online is the open access institutional repository for the University of Wollongong. For further information contact the UOW Library: research-pubs@uow.edu.au 


\title{
Intellectual entrepreneurs and the diffusion of ideas: two historical cases of knowledge flow
}

\begin{abstract}
This article argues that the diffusion of concepts and theories from one culture or society to another requires the active engagement of a category of agents which I identify as 'intellectual entrepreneurs'. Two historically contrasting cases of the transmission of ideas are examined in order to explain the processes whereby alien concepts are diffused across cultures. Foreign ideas and concepts that are successfully assimilated into a culture are neither automatically accepted nor externally imposed. Rather, knowledge flow succeeds on the basis of selection and transformation by local intellectual entrepreneurs who at the same time transform the receiving context to accommodate the modified foreign ideas. The activities of individuals, as intellectual entrepreneurs, are identified and discussed in order to indicate the processes through which alien concepts and theories are diffused into a receiving culture.
\end{abstract}

\section{Keywords}

entrepreneurs, diffusion, ideas, two, historical, cases, flow, knowledge, intellectual

\section{Disciplines}

Arts and Humanities | Law

\section{Publication Details}

Qi, X. (2013). Intellectual entrepreneurs and the diffusion of ideas: two historical cases of knowledge flow. American Journal of Cultural Sociology, 1 (3), 346-372. 
American Journal of Cultural Sociology Volume 1 Issue 3

\title{
Intellectual Entrepreneurs and the Diffusion of Ideas:
}

Two Historical Cases of Knowledge Flow

\section{Xiaoying Qi}

\begin{abstract}
This paper argues that the diffusion of concepts and theories from one culture or society to another requires the active engagement of a category of agents which I identify as 'intellectual entrepreneurs'. Two historically contrasting cases of the transmission of ideas are examined in order to explain the processes whereby alien concepts are diffused across cultures. Foreign ideas and concepts that are successfully assimilated into a culture are neither automatically accepted nor externally imposed. Rather, knowledge flow succeeds on the basis of selection and transformation by local intellectual entrepreneurs who at the same time transform the receiving context to accommodate the modified foreign ideas. The activities of individuals, as intellectual entrepreneurs, are identified and discussed in order to indicate the processes through which alien concepts and theories are diffused into a receiving culture.
\end{abstract}

Key words: intellectual entrepreneur, diffusion, Schumpeter, Buddhism, Social Darwinism

Xiaoying Qi (School of Humanities and Communication Arts, University of Western Sydney) (Corresponding author email: s.qi@uws.edu.au) 


\section{Introduction}

Two historical cases of the transmission of ideas into China, from ancient India and also modern Europe, are examined to explain the processes whereby alien concepts are diffused across cultures. The process of knowledge diffusion is treated in terms of the activities of 'intellectual entrepreneurs' who combine ideas in new ways, paying attention not only to the selection of alien concepts which they develop, deploy and elaborate but also to the modification of the existing culture or intellectual framework into which the transformed concepts are inserted. In their combination of elements from both foreign and domestic contexts intellectual entrepreneurs make something that had not previously existed and which can operate as a newly introduced knowledge only after the resistance of the established intellectual framework is overcome.

The diffusion of foreign knowledge into China has typically been mediated by Chinese preferences rather than subjection to alien determination. Indeed, this is an enduring theme of Chinese intellectual contact with external forces, of selective apprehension and adaptation, of simultaneously appropriating and transforming ideas from foreign sources. This well-developed pattern in Chinese history includes the sinicization of Indian Buddhism from the first century to the Mongol invasion of the thirteenth century and the two-hundred-and-fifty year period of Manchu reign from the seventeenth century. Even the period after the Opium Wars, in the midnineteenth century, until 1949, when China experienced historical subordination to Western political, economic and military dominance, the diffusion of knowledge into China principally occurred through the engagement of intellectual entrepreneurs who intentionally directed their efforts to the development of counter-Western strategies.

In order to examine the mechanism of knowledge diffusion this paper examines two contrasting cases. The diffusion of Buddhism into China during the medieval period occurred 
when China's integrity was intact. Western modernism, on the other hand, was first introduced when China experienced profound political and economic disadvantage generated by Western military might. These quite different contexts permit examination of knowledge diffusion which accounts for a general transformation of China's cultural and intellectual milieu. While Buddhism was assimilated into a society relatively insulated from foreign influence Western ideas were introduced in response to the alien encroachment to which China was subjected. The role of intellectual entrepreneurs in both cases is examined to indicate the contrasting but continuous ways in which alien thought is adapted to a receiving framework which is itself modified through the efforts of intellectual entrepreneurs to adopt, transform and integrate ideas borrowed from an alien setting.

\section{The Diffusion of Knowledge and Intellectual Entrepreneurs}

The problem of understanding the transfer of concepts and theories, isolated ideas or ideational systems such as religions or technologies and associated techniques from one culture to another has been a concern of anthropologists, geographers and historians at least since the period of European colonization during the nineteenth century. The mechanism most generally referred to in explaining such knowledge flows is 'diffusion'. There are a number of issues surrounding this concept and how it is used in this context. One problem is precisely its association with Western colonization and the subsequent claim that the term and its application are euro-centric (Blaut 1977; 1987; 1993). In a book with the transparent title The Colonizer's Model of the Model: Geographical Diffusionism and Eurocentric History Blaut (1993: 14-17) argues that classical diffusionism holds that the world comprises two sectors, one of these is Europe, where invention, innovation and change naturally occurs, and the other - non-Europe - is stagnant, unchanging, traditional and backward. The movement of ideas or products in which 
ideas are embedded is from Europe to non-Europe in the form of diffusion, and in compensation for this diffusion of civilizing ideas non-Europe provides raw materials and labour to Europe. While Blaut (1993: 26-30) acknowledges that modern diffusionist theory differs from classical diffusionism in many respects he insists that its basic propositions remain more or less unchanged.

Blaut's critique is an important caution against such influential social theorists as Weber (1964), whose argument concerning the 'uniqueness' of the West, or what he calls the Occident, is premised on the idea, no longer hegemonic (Goody 1996; 2004; Blue 1999), that rationality is exclusively located in the historical experience of European institutional and religious development and denied to the historical experience of China, India and other Oriental societies. But Blaut's guiding concern ignores the fact that the major social scientific statement of diffusion by Kroeber (1940) is not based on the Euro-centricism that Blaut sees as its defining characteristic. Kroeber provides a number of examples of cultural diffusion, beginning with the 'stimulus' of Chinese porcelain on eighteenth-century European technology; he goes on to discuss ancient Phoenician and Egyptian contact, early Chinese-Japanese diffusion and many other cases in which European culture is not even mentioned. This is not to say that Kroeber ignores the diffusion of European ideas and technologies into non-European contexts, as in his discussion of the development of a Cherokee alphabet. But Kroeber's wide ranging examples tend to support McNeill's (1988: 75) view that 'diffusion of skill and knowledge from one community to its neighbours and neighbours' neighbours constitutes the central process of human history'. Given the ubiquity of diffusion it is necessary to know how it operates and in particular what mechanisms it employs.

Kroeber's account of mechanisms is sketchy and suggestive rather than precise. Nevertheless he describes some relevant aspects of the process of diffusion that are important background considerations. First, Kroeber (1940: 1) notes that diffused cultural material is 
frequently only a fragment of a larger complex or system and these fragments may be placed in a context in the receiving culture that is quite unlike their original context. This makes the process of diffusion not simply one of transfer but transformation. A connected idea which Kroeber (1940: 19) mentions is that diffusion does not operate automatically, the inference being that particular creative efforts are required on the part of those in the receiving culture who select and appropriate alien ideas and in doing so create something that did not previously exist: in diffusion there 'is historical connection and dependence, but there is also originality' (Kroeber 1940: 20).

One problem with classical diffusion theory as it is typically understood, however, is the assumption that diffusion simply spreads within a social system and that introduced ideas have an internal energy and power through which they spread. This approach simply ignores the social agents of diffusion and the processes they initiate and influence. It will be shown that diffusion depends on social agents of 'diffusion items'. 'Diffusion items', as Chabot and Duyvendak (2002: 706) point out, are taken up by 'critical communities' or 'networks of excluded citizens who identify new social problems, formulate new modes of thinking and feeling, and develop new political and cultural solutions'. The challenge taken up in the present paper is to conceptualize these agents and the processes in which they are implicated. To do so it is necessary to understand the social location of such agents and their relationship with both 'diffusion items' and the social system into which they are assimilated. Collins' (1998) discussion of knowledge creation and transmission, rather like Chabot and Duyvendak, holds that 'networks are the actors on the intellectual stage' (Collins 1998: xviii). But this arguably operates at too high a level of abstraction. Collins' idea that knowledge creation results from participation in networks, animated by emotional energy and empowered with cultural capital, is not challenged here. But it is not merely the 'social links among those thinkers whose ideas have been passed along in later generations' that generates new knowledge. Some locations within networks serve as more 
‘optimally marginal social spaces' than others, to use Mclaughlin's (2001) term, which more directly lead to creativity, insight and innovation. Both Collins and Mclaughlin are primarily concerned with the link between intellectual networks and innovation, in philosophy and psychoanalysis respectively, within common societal settings. This paper, however, is concerned with innovation through combinations of ideas across cultural and societal barriers, enacted by intellectual entrepreneurs, that is, how ideas are transmitted from one cultural or societal setting to another. The discussion to follow focusses on the necessary but neglected process of 'combining elements' from one cultural setting to another, and how it is achieved by the agency of the intellectual entrepreneurs involved.

The social role of an intermediary standing between diffusion items and the social system into which that item is introduced becomes clearer in the distinction between 'diffusion' and 'brokerage': McAdam, Tarrow and Tilly (2001: 333, 335) note that: 'Diffusion involves the transfer of information along established lines of interaction while brokerage entails the linking of two or more currently unconnected social sites ... [D]iffusion requires a much lower investment of time, entrepreneurship and frame transformation than brokerage'. The concept of brokerage, more directly than diffusion, indicates the means through which cultural objects are translated from one society to another. But it is not sufficient to say that brokerage is merely 'the formation of new links (or the consolidation of old ones) among transmitters and receivers' (Chabot and Duyvendak 2002: 708). Such an account of brokerage emphasizes the linking role at the expense of the creating role required of the translation of alien concepts and theories into an entirely new context. The problem is that 'brokerage' literally means no more than being a link or agent for another. The point raised by McAdam, Tarrow and Tilly in the quotation above is that their distinction is between a linkage requiring little facilitation and one demanding, in their words 'entrepreneurship and frame transformation'. Entrepreneurship and frame transformation, 
however, are rather more than brokerage. A similar point is raised in Fine's discussion of the changing reputations of historical figures: '[e]ven if reputations are grounded in history, they do not just happen: they must be sponsored' (Fine 2001: 21). Diffusion, like reputation, rather than spontaneously emerging requires 'entrepreneurs' who, in Fine's (2001:25) account of their role in reputation, 'use their narrative facility and institutional placement to control the way people remember historical figures'. Diffusion, to borrow Lee and LiPuma's (2002) description of circulation, is not simply 'a form of transmission or delivery' but 'a dynamic cultural phenomenon' (see also Aronczyk and Craig 2012). Similarly, in his discussion of international circulation of ideas, Bourdieu (1999) emphasizes that ideas are not transmitted of their own accord but their movement is consciously constructed and shaped to overcome constant resistance. Indeed, when received wisdom or dominant ways are challenged, resistance is unavoidably encountered (Frickel and Gross 2005: 207). Entrepreneurship and frame transformation, therefore, are terms which refer to complex social mechanisms of cultural diffusion in which purposive engagement is implicit. Frame transformation may include what Frickel and Gross (2005: 221) describe as 'packaging and dissemination' in ways that 'resonate with the concerns of those who inhabit an intellectual field or fields'. Just as importantly, however, such packaging and dissemination involves careful innovation. It is necessary to say careful innovation because the mechanisms involved are context dependent and therefore require attention to both content and reception.

The diffusion of cultural forms to be discussed below, within the context of Chinese history, did not involve a passive reception of foreign ideas but an active and innovative diffusion initiated by persons who carefully selected foreign ideas, de-contextualized them from their foreign origin and reorganized, reformulated and transformed them and, finally, re-contextualized them into a Chinese cultural framework which they modified. This process involves what Stark 
(1991) calls 'path dependence' in his account of the privatization strategies adopted in East Central Europe, in which 'the introduction of new elements take place most typically in combination with adaptations, rearrangements, permutations, and reconfigurations of already existing institutional forms'. This is the type of activity required to achieve what Kroeber (1940: 20) calls 'stimulus-diffusion', which involves, as noted above, 'historical connection and dependence, but ... also originality'. This engagement is effectively described in Schumpeter's classic statement of entrepreneurial activity. The particular nature of the entrepreneur's activities and approach is in their introduction of 'new combinations' into the economy. The general possibilities of the operations of entrepreneurship from the economy to the broader cultural arena are clear in Schumpeter's (2008: 84-86) discussion of the relationship between tradition and entrepreneurial activity. Established knowledge, Schumpeter (2008: 84) says, 'does not need to be continually renewed and consciously reproduced ... [as it] is normally transmitted almost without friction by inheritance, teaching, upbringing, [and] pressure of [the] environment'. The introduction of 'new combinations', however, which displace or change established knowledge, requires 'a new and another kind of effort of will', which Schumpeter (2008: 86) says must perform two tasks: it must 'wrest amidst the work and care of the daily round' a conception and realization of 'the new combination', and secondly, it must do this against 'the reaction of the social environment against one who wishes to do something new'. The 'characteristic task' of the entrepreneur, according to Schumpeter (2008: 92) 'consists precisely in breaking up old, and creating new, tradition'. This second crucial aspect of entrepreneurship is typically ignored in discussion of both Schumpeter and entrepreneurship. An assumed basis of successful entrepreneurial diffusion is shared social and cultural conditions (Rogers 1995: 7; Strang and Meyer 1993; Wejnert 2002). Obstacles to entrepreneurship must therefore include social and cultural differences or contrasts (Rogers 1995; Kaufman and Patterson 2005). 
The discussion of intellectual innovation and development is typically concerned with endogenous changes within established and contiguous fields (Collins 1998; Frickel and Gross 2005). Such discussions are frequently taken to be representative accounts of intellectual innovations as such. The transformation of ideas considered here, however, concern previously unconnected fields drawn from exogenous sources and intentionally developed by intellectual entrepreneurs to be diffused across distinct even opposed political, intellectual and cultural spectrums. The intellectual entrepreneur's creation does not derive simply from a struggle for 'prestige' or 'status' or 'attention', emphasized by Collins' (1998) in his discussion of intellectual change, although these may have been incidental outcomes of the activities of those discussed below. The drive for change which animated the Chinese intellectual entrepreneurs treated here surely included doubt concerning existing paradigms (Kuhn 1970) as well as complaints against dominant intellectual practices or expectations (Frickel and Gross 2005). More importantly though, a compelling sense of duty and mission to solve problems that transcended their own concerns and at the same time gave direction to those concerns, which informed the activities of all those who sensed that they were caught in the travails of momentous cultural change, cannot be understated in considering the cases of intellectual entrepreneurship discussed below. The anguished preoccupations of Kang Youwei (Kang Yu-wei) (1858-1927) are not atypical: 'I kept thinking of how hard people's lives were, and of how Heaven had given me the intelligence, talent, and energy to save them. Feeling deep sympathy for all things and lamenting the times, I thus dedicated myself to the ordering of the world' (quoted in Pusey 1983: 17). According to a recent intellectual account: 'Kang's quest for modern material civilization was an attempt to lift his country from weakness and poverty to wealth and power' (Wong 2010: 111).

The concept of the intellectual entrepreneur is developed below in the discussion of two cases of cultural diffusion. The introduction of both Buddhism and Western modernism into 
China constitutes major instances of foreign knowledge diffusion which produced significant change and had lasting cultural impact. Neither achieved its place in China through official endorsement nor foreign force nor through a 'power' in the ideas themselves to spread automatically. Neither Buddhism nor Westernism was accepted wholesale in China. Those Buddhist doctrines and elements of Westernism which have influenced Chinese culture are ones which were carefully selected and integrated into existing Chinese thought through transformation as 'sinicized' knowledge. Foreign ideas are accepted into Chinese intellectual heritage subsequent to their modification, mutation and synthesis with pre-existing local intellectual and conceptual patterns. And after the inevitable and often protracted resistance of the established cultural framework and its defenders are overcome. Such tasks are carried out by intellectual entrepreneurs who are able to select and combine foreign knowledge with the local stock of knowledge and transform it into effectively new patterns of thought and culture. The ideas that have been successfully diffused into China, to borrow Schwartz's (1985: 21) phrase, are "precisely the ideas that relate to already existing preoccupations of Chinese who live in history as well as in culture'.

\section{Intellectual Entrepreneurs and Sinicization of Buddhism}

Indian Buddhism was the only major ideological and religious import brought into China during the medieval period. Only after a series of transformations and local developments of accommodation, occupying almost 1000 years, did Buddhism eventually gain sufficient prominence in China to become assimilated into a modified Chinese intellectual heritage (Hsu 2001: 445; Wright 1990: 1-33). During its early years in China Buddhism was regarded simply as a foreign discourse; it was practiced only among the missionaries who attempted to proselytize to a largely uninterested Chinese population. The political and social environment in China at this 
time was not conducive for Buddhism to proliferate and thrive. During the Han period (206 BC220 AD) Confucianism, which had intellectually enriched itself by integrating elements from competing local schools of thought, enjoyed the status of an institutional state orthodoxy (Wright 1959: 15). As a minor alien belief system Buddhism drew no intellectual attention from the Confucian literati.

It should not be concluded from the above remarks that the adaptation of a system of thought as a state ideology is sufficient for it to have a pervasive social presence, as Confucianism did. Indeed, there was an historical period in a northern Chinese state when Buddhism became the state ideology, but this in itself did not translate into its integration into the broader compass of intellectual, social or religious life. Around 317 AD the Tuoba people established themselves as political rulers in the north and founded Bei Wei, the Northern Wei dynasty. The Tuoba had a strong sense of their own ethnic identity and way of living which set them apart from the majority ethnic Han population against whom they had a sense of distance and even hostility that was occasionally manifest in conflict. Given the strong antipathy between the Tuoba and the Han it was unthinkable for the Tuoba rulers of the Northern Wei to adopt Confucianism as a state ideology because they saw it as thoroughly Han. Buddhism, as a foreign - that is non-Han - discourse had an obvious appeal to the Tuoba, which was re-enforced by what they saw as the magical and superhuman elements of Buddhism, close to their own thought system (Wright 1959: 55-57). And yet, the upholding of Buddhism by some Tuoba leaders did not provide Buddhism with the prominence it later acquired in China through quite different mechanisms.

While state sponsorship was not sufficient for the domestic acceptance of Buddhism in China, neither was it dependent on an increase in the numbers of foreign missionaries active in China. It is often argued that the integration of Buddhism into Chinese thought and practice was 
generated by the quantity and authenticity of translation of Indian Buddhist scriptures into Chinese (Shen 1997: 47-50; 100-111). The discussion below shows that Chinese acceptance of Buddhist doctrine was not generated by such factors but through the endeavors of intellectual entrepreneurs to both employ and transform local categories in domesticating an erstwhile foreign philosophy. The meaningful diffusion of Buddhism in China began to occur when the propagation and proselytizing of Buddhism was transferred from foreign missionaries to local intellectual entrepreneurs. The Buddhist doctrines which had an enduring presence and influence in China are those which were incorporated into and synthesized with existing Chinese teachings and thereby transformed from a foreign Indian Buddhism into a local Chinese Buddhism. This process was facilitated by particular developments in Chinese thought and ritual practices, especially in Daoism, which effectively functioned as conduits for the sinicization of Buddhism.

During the second century, toward the end of the Han dynasty and subsequent to it immortality cults developed throughout China, especially in the south, which adopted the Daoist name although the majority of their sacred texts were more recent than the classics of Daoist philosophy, the Daodejing and the Zhuangzi, and their doctrines were eclectic amalgams of local folk religions. The practitioners of these cultic religions 'were particularly desirous of knowing whether Buddhism could add to their knowledge of elixirs and practices that would contribute to longevity, levitation, and other superhuman achievements' (de Bary, Chan and Watson 1960: 273). The interest of Daoist aspirant immortals in the possibilities provided by early Buddhist rituals, breathing and gymnastic exercises, dietary management, charms and talismans provided an opportunity for missionaries to disseminate these and related aspects of Buddhism and engage in translating and transforming those scriptures and developing those practices which enhanced intuitive faculties. The Daoist receptiveness to aspects of Buddhism was not only selective but also transformative of the Buddhist practices in question. 
By the third century a number of developments converged in providing possible opportunities for Buddhism to find a place in Chinese culture. With the breakdown of the Han dynasty the influence of Confucianism declined and the appeal of Daoism grew. There was also, as a consequence of these political and religious changes, a widespread sense of general social and intellectual discontent. Together these trends generated a climate in which new ideas and attitudes would become attractive and find potential audiences (Wright 1959: 21-41). But whereas a number of social circumstances changed in a way that might have favoured Buddhism, as a 'barbarian' religion which was antinomous with accepted Chinese cultural norms, it continued to encounter doubt, criticism and opposition. Buddhist temples were widely seen as constituting a foreign source of loyalty and therefore detrimental to government rule and a Buddhist's life required rituals and commitments that were regarded as violations of the canons of established, that is, Chinese social life (Zürcher 2007: 255). These and other issues of concern highlighted the notions subject to repackaging and transformation by localizing Buddhist intellectual entrepreneurs who now capitalized on existing accepted ideas and beliefs as media of diffusion, showing how Buddhist notions were congruent with Chinese cultural norms. According to Buddhist apologetics, then, Buddhist temples contributed to social stability and prosperity; in their activities and practices, it could be claimed, Buddhists attempted to attain the highest perfections of Confucianism and Daoism (Zürcher 2007: 255-256). The ideas of Buddhism, which prior to this time had been seen only as a foreign ideology, now began to be articulated in a local Chinese vocabulary and cosmology. As Fang (2002) notes, Buddhism from this time is promoted in terms of existing concepts in Chinese philosophies, especially those of religious Daoism (also see Tsukamoto 1985). Against the earlier dissemination of Buddhism as a set of doctrines that not only originated in India but which were expressed in a South Asian idiom, by the third century the forms of Buddhism that prevailed in China was interpreted in terms of a 
Daoist vocabulary and set of concerns (de Bary, Chan and Watson 1960: 273). Indeed, Buddhism was so tightly wrapped in Daoist robes that it was common to regard Taoist and Buddhist scholars as belonging to a single intellectual trend' (Fung 1953: 240).

In popularizing and domesticating Buddhism in China early local converts who operated as intellectual entrepreneurs borrowed extensively from Daoism in their translations of Buddhist notions and ideas, shaping and accelerating diffusion through 'culturally analyzed similarities' (Strang and Meyer 1993: 487). The Chinese concept of wuwei (effortless action), for example, while not exclusively Daoist - it has a single appearance in Confucius' Analects (Confucius 1979: 132) - has a significant role in Daoist thought which is carried across into the sinicized Buddhism that emerged in the third century. The Buddhist concept of asamskrta, which signifies an uncaused or unconditioned state or existence, is translated as wuwei (Lusthaus 1998: G002SECT2). Wuwei was also used for the Buddhist term nirvana (freedom from human suffering) (Mou Tzu 1994: 617) although later replaced by a transliteration of nirvana as niepan. In its sinicization, Buddhism was shown to be compatible with and not contradictory to Chinese traditions. As a strategy to remove resistance, 'some passages and expressions deemed offensive to Confucian morality were bowdlerized or omitted' (Wright 1959: 36). For instance, instead of literally conveying the Indian Buddhist message that 'the wife comforts the husband', which appears to place a woman in a position of marital control, in the Chinese form of Buddhism the phrase becomes 'the wife reveres her husband' in order to ensure its conformity with Confucianism's notion of wifely subservience.

The first text written in the Chinese language about Buddhism, Li-huo Lun (Treatise on the Removal of Doubt), composed in the name of Mou Tzu (Mou Zi) in the late second century, is widely regarded as 'is an important source of information for students of early Chinese Buddhism' (Chen 1964: 36). The text characteristically addresses a series of questions which 
arose from concerns regarding the foreign origins of Buddhism and aims at removing antagonism to an alien ideology. If the way of Buddha was the greatest and most venerable way, then why was it not mentioned in the Classics of the Sages and why did Confucius not practice it? Questions of this sort were answered in order to dispel any concern and cast off opposition, showing that there was no contradiction between Buddhism and Chinese traditions. In answering the questions regarding the possibility of a Chinese adherence to the originally foreign doctrines of Buddhism Mou Tzu drew on Confucian and Daoist thought in expounding a version of Buddhism that could be seen to be compatible with and not challenge accepted Chinese beliefs and understandings.

From the very beginning in his introduction when answering questions about Buddha Mou Tzu (1994: 59-61) employed Chinese rather than Indian idiom through the description of Buddha's amassing 'the power of the Way [dao]', 'yin and yang' interpenetrating and attaining 'nonaction [wuwei]' [nirvana]. Instead of using imported Buddhist categories Mou Tzu deliberately utilized familiar Chinese classics, Confucian and especially Daoist notions, to remove the reader's doubt and alienation about as well as antagonism toward a foreign religion, indicating that Buddhism was consonant with a Chinese cultural framework. When challenged why Emperors Yao and Shun, or the Duke of Chou, or Confucius did not practice Buddhism and there was no mention of Buddhism in the Chinese Seven Classics, Mou Tzu (1994: 79) made reference to the Analects and The Record of Rites, both parts of the Seven Classics, to rebuke the critic. Mou Tzu makes the point that these four sages studied with teachers from non-classical traditions and it was not whether Buddhism was mentioned that matters but whether it is in harmony with the classical cultural framework. Similarly, in defending Buddhism's rejection of wealth, position and pleasures, Mou Tzu (1994: 119) drew on both the words of Confucius 'Poverty and low station are what men dislike, but even if I did not get them in the right way I 
would not try to escape from them' and Laozi 'The five colours make men's eyes blind, the five notes make his ears deaf, the five tastes injure his palate, riding and hunting make his mind go wild with excitement; goods hard to come by serve to hinder his progress'. It is, as Keenan (1994: 10) says, 'a conscious and creative rhetorical strategy of cultural adaptation (presaging the later "matching concepts" methodology), whereby the foreign Buddha and his doctrine are progressively mediated in terms of Chinese culture'.

In overcoming resistance and domesticating an alien Buddhism intellectual entrepreneurs not only transformed Buddhist notions but also shifted the Chinese cultural framework through reinterpretation and reconstruction of Confucianism and Daoism. Practices which were distasteful to Chinese mores, such as the Buddhist monks' shaving their head, which contravened Confucian virtue of filial piety by injuring a body endowed by one's parents, were rationalized and reinterpreted by Mou Tzu (1994: 84) in an argument that 'Confucius once said, "A man good enough as a partner in the pursuit of the Way... need not be good enough as a partner in the exercise of moral discretion"'. Mou Tzu made his point through providing a number of counterexamples reinterpreting the norm of filial piety that one should excise moral norms according to concrete cases. Throughout the text Mou Tzu makes very few references to Buddhist scriptures, and when he does he provides no direct citation and instead makes extensive reference to Confucian and especially Daoist sources. The primary purpose of the text, then, is not to explain Buddhism doctrine but to convince the Chinese reader that Buddhism is not in violation of the established Chinese cultural framework and also prepare the Chinese cultural framework for reception of Buddhism through reinterpretation of Confucianism and Daoism. By drawing on Confucianism and Daoism Mou Tzu is able to demonstrate that while Buddhism had a foreign origin its acceptance in China was not contrary to or disruptive of the Chinese intellectual heritage. Mou Tzu's intellectual entrepreneurship is primarily directed to overcoming local 
resistance to a foreign doctrine and reconstructing the Chinese cultural framework in reception of a now indigenized Chinese Buddhism.

While numerous schools of Indian Buddhism were imported to China over a period of more than three hundred years only those which were synthesized with Chinese thought endured. Indeed, by the eighth century Buddhism in China had become successfully indigenized and had no meaningful contact with the Indian sources or interpretations from which it originally arose. By this time, according to Lusthaus (1998: G002SECT1), the Chinese had 'lost interest in Indian commentaries and treatises and instead turned their attention toward Chinese commentaries on the Buddhist scriptures - such as the Lotus Sutra and Huayan Sutra - that had assumed importance for Chinese Buddhist traditions'. Tiantai (Lotus), Huayan, Pure Land and Chan schools, as Chen (1964: 297) emphasizes, 'were no longer Indian systems introduced into China, but were really schools of Chinese Buddhism'. From the tenth century Chan Buddhism was 'essentially a Chinese product' (Hsu 2001: 445) and from this time was established as one of the dominant teachings in China, along with Confucianism and Daoism. It is this school of Buddhism which later spread to Japan as Zen Buddhism, and becomes one of the most influential form of Buddhist teaching.

The translation of Buddhism from India to China did not only mean that it acquired a Chinese idiom but also that its philosophical concerns were closer to those of the Chinese intellectual traditions than the Indian. Chinese intellectual entrepreneurs modified 'the antifamily and antisocial concepts of Buddhism in India ... so that filial piety was still a virtue to be observed' (Chen 1964: 486; see also Chen 1973: 14-64). Indeed, reincarnation was reinterpreted to be commensurate with and understood through ancestor worship. While Indian Buddhism was not concerned with the notion of human nature, for instance, and many schools even rejected the very concept of essential nature, intellectual entrepreneurs of leading schools of Chinese 
Buddhism during the Tang dynasty (618-907 AD) - under the influence of Confucian thought inquired into and debated the concept of Buddha-nature. The two dominant schools of Buddhism during this period were the Huayan or Flower Garland School (Cook 1977) and the Tiantai or Lotus School (Swanson 1995). What principally distinguishes these schools is their understanding of human nature refracted through Mencius's idea that human nature is inherently good. While the doctrines of the Huayan School held that Buddha-nature is essentially pristine and good, the Tiantai School held that Buddha-nature is not perfect and pure but contains elements of evil and impurities. Whereas the Huayan position reflects Mencius's argument concerning the inherent goodness of human nature that of the Tiantai derives from the Daoist notion of paradoxical integration (Qi 2014). The Tiantai contention is that good and evil, pure and impure are complementary opposites and the Buddha-nature's evil traits are necessary in order to understand and have compassion for ordinary sentient beings.

In metaphysics also Chinese Buddhism has more in common with traditional Chinese teachings than it has with Indian Buddhism. Indian Buddhist doctrines are characterized by a number of fundamental dichotomies, including those between spirit or pure mind and the phenomenal world or matter, between being and non-being, existence and non-existence, between consciousness and bodily existence, and so on. Chinese Buddhist doctrines, on the other hand, tend to take a typically Chinese or 'middle-path solution to the issue of duality', as Lai (2008: 268) puts it, which is expressed in both the Tiantai and Huayan Schools of Buddhism, one proposing an integration of 'consciousness and the phenomenal world' and the other emphasizing 'the interdependence of everything' (Lai 2008: 268), positions which derive from Daoist teachings.

In the process of enculturation of Buddhism, intellectual entrepreneurs further transformed the Chinese cultural context. Indeed, institutional elements were borrowed from 
Buddhism in the organization of religious Daoism, and temple Daoists constructed a clergy by imitation of the religious orders of Buddhist monasteries (Hsu 2001: 445). They also adopted many ritual methods employed in Buddhism. During the Song dynasty (960-1279) the philosophical developments which produced Neo-Confucianism as a distinctive philosophy included borrowing from the now Chinese Buddhist system of thought (Fung 1953; see also Huang 1999). Buddhism's metaphysics of nature was reconstructed and incorporated into neoConfucianism (de Bary 1959: 33). Zhu Xi, the authoritative formulator of neo-Confucianism appropriated significant elements of Buddhism philosophy (Huang 1999: 128) and used them to develop a cosmology, a set of metaphysical notions, a cluster of psychological concepts to strengthen the Confucianism tradition (Wright 1959: 90), and in doing so modified it significantly. Drawing on Buddhist's $l i$ (absolute principle) and shi (facts or events) metaphysics Zhu Xi developed dialectic of $l i$ (principle) and $q i$ (material-energy) (Lusthaus 1998: G002SECT14). Through these appropriations of Buddhist ideas Confucian intellectual entrepreneurs thus further transformed existing Chinese cultural norms to adjust it to the needs of a changing social and cultural milieu.

The diffusion of Indian Buddhism into China and its eventual sinicization occupied a long period of historical time, roughly from the first century until the ninth century AD, during which facilitating social, philosophical and religious changes played crucial roles, and the endeavours of intellectual entrepreneurs, such as Mou Tzu, were essential. It has been argued above that neither state sponsorship nor missionary activities were themselves sufficient for the Chinese acceptance of Indian Buddhism. Rather the development of religious Daoism in the second century provided a positive basis for the apprehension and integration of aspects of Buddhist ritual practices into Chinese developments by intellectual entrepreneurs which initiated a process of transformation of originally Indian ideas into Chinese terminology and conceptualization, harmonizing the alien 
thought and practices with pre-existing Confucian and Daoist concepts. By the sixth century distinctive doctrinal strands of Chinese Buddhism had been constructed, which related the debates that had shaped the philosophical development of both Confucianism and Daoism to a now recognizable Chinese Buddhism, distinct, and quite 'separate from Indian Buddhism' out of which it had ostensibly originated (Lai 2008: 235), although to put it this way neglects the Chinese sources from which it grew. The advent of a Chinese Buddhism was a significant factor in the transformation of the Chinese intellectual heritage on which it necessarily drew. Throughout the process of the sinicization of Buddhism the Chinese intellectual heritage which was the standard toward which it gravitated was never static and unchanging. The dynamic interaction between the different elements of China's intellectual heritage which ensured its almost constant transformation continued after the consolidation of Buddhism's sinicization.

It is clear from the discussion above that its acceptance into China required that Buddhism was subjected to a process through which its terminology, philosophical concerns and general ethos were disconnected from its Indian origins and harmonized with prevailing Chinese concepts and understandings. It has been shown that the diffusion of Buddhism into China did not occur automatically but rather was achieved through the efforts of intellectual entrepreneurs who carefully selected elements of concern to Chinese subjects, combined them with local thought and transformed them in a way which harmonized them with a pre-existing intellectual heritage.

\section{Modern Ideas and Intellectual Entrepreneurs}

Modern Western ideas were first transmitted into China at a time of national humiliation through defeat in the Opium Wars of the mid-nineteenth century. Subdued by the superior weapons and tactics of the allied Western forces, China in defeat was forced to sign a number of 
'unequal treaties' which benefited Britain, France, Russia and the United States. These unequal treaties allowed a number of significant concessions to be made by China to Western powers, including the extraterritoriality and consular jurisdiction of foreigners in China, effectively removing foreigners on Chinese soil from the sanction of Chinese authority, restriction of the level of customs duties paid by foreigners, the provision of foreign settlements, concessions and leased territories within China, provision of freedom of movement for foreign ships in Chinese inland and territorial waters, legalization of the opium trade, freedom of missionary activities in China, and other concessions too numerous to mention (Spence 1999: 180-183). China's subordination to Western powers through defeat in the Opium Wars provided foreigners with access to China's economic resources but did not grant them political or cultural control over China. China was not formally colonized by Western powers as occurred during this period in Africa, the Pacific and South East Asia.

The response to these foreign threats, encroachments and incursions took various forms. The official Chinese response was resigned capitulation reflecting political incapacity, entrenched conservatism and intellectual malaise. Young urban Chinese, on the other hand, affronted by European incursion and embarrassed if not dismayed by official Chinese ineptitude and weakness began looking for intellectual and political solutions. One means of reasserting Chinese prerogative was to carefully select elements of Western knowledge that might be useful for a new development of China. This was not to overthrow existing patterns of thought and culture but to integrate and effectively localize foreign knowledge in order to attain its perceived power. There was a widespread hostility to Western forces among all classes of Chinese people, and a strong desire to not capitulate to or appropriate wholesale Western concepts, theories or practices. At the same time there was a growing recognition from the late nineteenth century that the best defense China had against Western power was the careful appropriation of those ideas and practices that 
were responsible for Western strength. In Chinese hands these would hold at bay the humiliation of China. The task of selecting and shaping Western concepts for Chinese development was executed by China's young intellectual entrepreneurs.

It would be naïve to claim that there was unanimous agreement among these Chinese intellectuals and officials about how Western knowledge should be treated. The intellectual entrepreneurs who endeavoured to transform and integrate Western knowledge into a reformed Chinese culture met with strong criticism and attacks from those who supported repudiation of Western ideas and preservation of China's traditional thought and also those who called for wholesale Westernization and abandonment of Chinese traditional thought. The intellectual entrepreneurs discussed below argued that it was only through learning from the West that China could build up its power but at the same time that it was necessary that learning from the West did not entail capitulation to it and abandonment of a sense of Chineseness, of a national essence. The course selected by a significant number of intellectual entrepreneurs entailed the appropriation, transformation and integration of particular Western ideas useful for the defense and integrity of China against the West.

The Chinese intellectuals who participated in these new developments were close to the Western and modern notion of intellectuals described by Gouldner (1979: 48) as a social type whose 'interests are primarily critical, emancipatory, hermeneutic and hence often political' who may 'contribute to revolutionary leadership'. The critical and hermeneutic aspect of the intellectual's practice is stressed by Hannerz (1990: 246) when he identifies the ability of intellectuals to both de-contextualize and re-contextualize knowledge. The dual process of decontextualizing and re-contextualizing European cultural ideas to best suit China's needs was the task which principally identifies these developments. It must be noted, however, that the culturalintellectualistic approach employed did not itself derive from Western cultural forms. It was, 
rather, as Lin (1979: 49) says, 'primarily molded by a deep-seated Chinese cultural predisposition as embodied in a monistic and intellectual mode of postclassical Confucian thinking'. One of the most important aspects of Confucianism lay in its emphasis on the primary function of intellectual experience. Although the doctrines of Confucianism were strongly attacked by a number of reforming intellectuals at this time, these reformers nevertheless practiced the values and form of Confucianism which emphasized learning, cultivation of mind and an ethical orientation in relations with others. Lin (1979: 50) explains that 'the intellectualistic climate of opinion of Confucian culture was so pervasive and deeply embedded that a category of analysis of the Chinese intelligentsia was decisively molded by it without their being aware of the fact'.

In assimilating Western concepts into a Chinese context these intellectual entrepreneurs would therefore at the same time also identify, strengthen and promote established or traditional concepts which were thought to be useful in a reconstructed national identity. They 'appropriated Western ideas, adapted them to local conditions and used them to rethink, reevaluate and reformulate the Chinese past and articulate visions of Chinese modernity' (Fung 2010: 5). It will be shown here that the appropriation of European ideas by Chinese intellectuals at this time was therefore frequently in the context of an intellectual assimilation that paradoxically reinforced key aspects of the local elite culture through the sinicization of alien concepts.

Although there was widespread agreement concerning the enormous differences between the Western and Chinese intellectual traditions some Chinese intellectual entrepreneurs began by discovering functional equivalents of Western ideas in China's intellectual heritage. In the adaptation and assimilation of a Western concept, then, the concept in question was given a place in a pre-existing Chinese intellectual context. Through this translation the alien concept was transformed by being sinicized and the framework of the diffused ideas was provided with a vitality it may have previously lacked. For instance, Western individualism was seen by some 
intellectual entrepreneurs as having a parallel form in the libertarian and anti-authoritarian strands of Daoism. Similarly, the pragmatic and utilitarian approach to statecraft was seen to have Chinese precursors in the work of the fourth century BC thinker Mozi and the Legalist School of the same period (Furth 2002: 15-16). The nineteenth-century reformers and intellectual entrepreneurs Yan Fu (Yen Fu) and Liang Qichao (Liang Chi-chao) were able to locate germs of ancient democracy in Mencius' idea that a ruler who failed to take note of popular opinion should be overturned (Mencius 2004: 121). More broadly, the Mandate of Heaven, which was not a doctrine of divine right but rather included the idea that rulership had to be merited by performance, and therefore implied a contingent right of rebellion, was seen to be reminiscent of the idea in Locke's liberalism that the relationship between government and governed is one of trusteeship and that a breach of this trust justifies rebellion (Locke 1963: 348-350; 459-462). Even the idea of science as regulated observation of nature that developed in Europe was seen by some Chinese intellectual entrepreneurs as parallel to elements of Daoist naturalism, a position that resonates with Needham's identification of the Daoist basis of traditional Chinese science (Needham 1956).

The evolutionary thread that connects these notions is present in the work of the highly significant intellectual entrepreneur Yan Fu (1854-1921), who in 1898 translated and introduced Thomas Huxley's Evolution and Ethics. This translation had a significant impact on Chinese thinkers at the time (Schwartz 1969: 98-112). Chinese intellectuals and young people during this period were inspired by the ideas of Darwinian natural selection and Herbert Spencer's notion of the 'survival of the fittest'. These ideas formed an ideological framework for major political, educational and cultural reforms in China. Yan $\mathrm{Fu}$ continued his efforts to diffuse into China Western philosophical, economic, social science and political ideas through further translations, 
including those of such major texts as Adam Smith's Wealth of Nations, John Stuart Mill's On Liberty and Herbert Spencer's Study of Sociology.

The perceived benefit to China of Social Darwinism encouraged Yan Fu to embrace it and in appropriating it to suit Chinese needs he transformed it. While Christian missionaries first brought Darwin to China his name was practically unknown to Chinese thinkers until Yan Fu began to write about him in 1895. Yan Fu's introduction of Darwin and Darwinism to China was partial in the extreme as he accentuated and reinforced the idea of 'survival of the fittest' at the expense of a statement of the 'full theory of evolution' (Pusey 1983: 78). Yan Fu's ultimate interest did not lie in exposition of a Western scientific theory but in its utilization for Chinese developmental purposes. In the aftermath of China's defeat in the Sino-Japanese War (1894-1895) Yan Fu saw the need for China to reform as a matter of survival. His introduction of the notion of 'survival of the fittest' was to compel the Chinese government and people to face what he saw as the impending danger of China's collapse. Yan Fu's solution was to encourage the idea that the Chinese people should work together as a group struggling for their nation's survival. In his creative development of Darwinism Yan Fu fails to mention that Darwin's conception of 'the ultimate cause of the transformation of species' derives from 'the struggle within species' (Pusey 1983: 64). He turns instead to the early Confucian philosopher Xunzi, who held 'that man is nobler than all animals because he can ch'un [group]'; in doing so Yan Fu completely sidesteps the competitive individualism that characterized Social Darwinism in Europe and America. For Yan $\mathrm{Fu}$ survival of the fittest pertains to the struggle between groups, and this is what he disseminated in his advocacy of Darwinian thought in late nineteenth century China. Yan Fu did not fail to understand Darwin's theory of evolution but, on the contrary, he chose to interpret it in a way which he thought was meaningful to China's circumstances. As an intellectual entrepreneur Yan Fu selected elements from the theory of evolution, combined them with aspects 
of Chinese resources and created entirely new notions. His endeavours were to 'inaugurate a new age of philosophical Chinese thought' (Pusey 1983: 78).

Influenced by Adam Smith's social theory, Yan Fu came to represent those who advocated the development of capitalist economy in China (Schwartz 2002: 103-105). What is of particular interest in this context, though, is that after completing a translation of Mill's Logic Yan almost immediately went on, in 1903, to publish a series of marginal commentaries on a new edition of Lao-tzu's (Laozi's) Tao te ching (Daodejing). This was not only because, as Yan writes, that 'only the views of Lao-tzu are compatible with the views of Darwin, Montesquieu, and Spencer' (quoted in Schwartz 1969: 198) but also because, as Benjamin Schwartz (1969: 197) puts it, 'Yen Fu's universe had never been neatly divided into the two incommunicable spheres of "Chinese tradition" and "modern West". Yan Fu represented those thinkers who saw the necessity of adopting ideas from the West to be used in China's best interest while also maintaining cultural nationalism, or ethno-nationalism. Ethno-nationalism is distinguished from civic nationalism by virtue of its connection with the ascribed cultural and historical characteristics of a people (or ethne), rather than with rights-based notions of national citizenship which are indifferent to cultural background (Connor 1994). Since ethno-nationalism conceives itself as an organic expression of popular consciousness, it is regarded as rooted in nature as well as history. Metaphors of awakening are thus understood by partisan nationalisms as the people resuming their natural dispositions (Holton 2005: 117).

Yan Fu's introduction of Darwinian and related thought into China was not a mere transplant of European ideas to Chinese soil. Rather it fits a general pattern in which Chinese intellectual and cultural borrowing involves practices in which Chinese intellectual entrepreneurs 'assimilated and responded creatively to Western ideas in various ways' (Clarke 1997: 29). Rather than being Westernized particular intellectual entrepreneurs in China selected specific 
Western ideas which were then cautiously diffused into the existing ferment to better understand them, with Chinese thinkers and activists critically appraising their relevance for China's selfimprovement. This process was conducted mainly to self-consciously resist and deflect foreign influence, and in the process strengthen China so that it did not imitate or become a 'copy' of the West. Through this process of selection, absorption and transformation the original Western concepts typically became part of an expanded and developing Chinese knowledge base, indeed become seemingly thoroughly assimilated elements of Chinese thought.

Even though a conduit and active agent for the diffusion of modernizing Western texts in China it is not at all contradictory for Yan to sign a petition in 1913 circulated by the 'Society for Confucianism', supporting the idea that Confucianism could act as a stabilizing common faith in China (Schwartz 2002: 111). Yan made use of the resources of the classical Chinese philosophical vocabulary and in doing so provided an original interpretation of Western thought. Although he was inspired by Spencer's Social Darwinism, his view that intellectual change in China should be accomplished through education, as Schwartz points out, did not derive from Spencer. This idea can be sourced, rather, in Confucius's ideal of the role of education in selfcultivation and especially in his follower, Xunzi's approach to education as underpinning moral development. Yan saw the value of Western thought for the modernization and revitalization of China, but his inspiration was rooted in the intellectual heritage of classical Chinese thought. Yan embraced Laozi's skepticism and his acceptance of evolutionary necessity was deeply informed by Laozi's anti-anthropomorphic naturalism (Furth 2002: 28; Tillman 1990: 64). For him, Laozi was the "antique source of a democratic spirit of personal independence and social "yielding", (Furth 2002: 36).

Parallel to but independent of Yan, a similar sinicized Darwinism was developed by Kang Youwei who is remembered for the idea of datong (Grand Unity) (Kang 1958), in which 
evolutionary notions were seen to resonate with aspects of Chinese traditional thought. Inspired by Darwinian thought Kang developed a theory of progress that drew upon and elaborated a Confucian framework. From the idea of an evolution of historical formations, through the interaction between organism and environment, Kang developed the proto-socialist idea of a common sharing. He believed that the evolutionary process which led to the formation of new species through an organism's adaptation to a changing environment would also lead to a growth of interdependence in human society which was productive of increasingly common sharing of environmental resources, including material wealth. Again, this is a conclusion quite opposite to the one drawn by the Social Darwinism that developed in Europe and America. Kang's elaboration of evolutionary thought into economic equalitarianism is seen by Furth (2002: 20) as a development of Mencius' idea of an extension of benevolence. It is just as likely, however, that Kang's evolutionism drew upon similar ideas in philosophical Daoism as expressed in a number of chapters in Daodejing. In any event Kang's evolutionism imbues the traditional Chinese concepts in the context of which it now operates with a new relevance and meaning.

While the endeavours of intellectual entrepreneurs were directed to the incorporation of Western modernism into Chinese consciousness it is important to appreciate how their doing so required at the same time fundamental modifications of the existing cultural framework. Inspired by Spencer's three energies, the physical, intellectual and moral, Yan Fu developed the three people's strengths, minli (people's physical prowess), minzhi (people's knowledge) and minte (people's virtue) (Pusey 1983: 65). Through the development of the social organism of three people's strengths, China would be able to be fit, to survive, and to advance. Rather than emphasizing moral ethics which was held in Confucianism to be the paramount factor for a state's strength, Yan Fu attributed more significance to minli (people's physical prowess) and minzhi (people's knowledge). It is this latter emphasis on the formative capacities of the people 
that violates the core of Confucian ethics and the Confucian world-view itself. Confucian ethics is based on the five cardinal relationships set out in the Mencius (2004: 60), but found in other classical sources including the Yijing (I Ching) and the Zhongyong (Doctrine of the Mean), namely those between father and son, sovereign and subject, husband and wife, elder and younger brother, and between friends. Ethical relations between persons require compliance to these particular roles which, with the exception of the last one, are structured vertically between superior and inferior. The emphasis on learning and self-cultivation in the Confucian system is to achieve role compliance of and within these cardinal relationships. There is an additional distinction in Confucian ethics, the distinction between the ethical responsibilities of ordinary people and of scholars. Ordinary people are required to practice self-cultivation in the sphere of family and community life but scholars must engage in self-cultivation in order to have responsibility for the distribution of cultural, social and political resources in the empire. It goes without saying that scholars are superior to ordinary people, who must respect their superiors. Yan Fu's idea of people's strength, necessary for his project, visibly and flagrantly challenged and violated the elitist core of Confucian ethics. It is interesting to notice that Kang Youwei circumvented the Confucian framework by not even including morality in his discuss of strength, but only acknowledged 'physical strength' and 'intellectual strength'. Obviously, ‘[a] nation's level of "evolution" for Kang was mainly judged in terms of materialistic achievements' (Wong 2010: 111). Though morality is included in Yan Fu's account, it was completely different from Confucianism's interpretation as an individual's giving up everything for righteousness. Yan Fu redefined it as public-spiritedness, which required that Chinese people work together selflessly for their nation's survival and strength (Pusey 1983: 66). The resistance of the literati and other defenders of the Confucian order of late Qing China to Yan and Kang was strenuous but 
ineffective as their own social and cultural power was undermined by Western demonstrations of the political ineffectiveness of the Qing Empire.

The contribution to Chinese intellectual innovation provided by Yan and Kang, among others, laid a foundation which was necessary to the New Culture Movement, which began in 1919, that relied on acceptance of the Darwinian premise of natural selection and Spencer's idea of the 'survival of the fittest'. According to the view expressed by the New Culture Movement, in order to survive in the modern world the Chinese citizen was required to be 'the fittest'. How this fitness was to be achieved required further transformation of the typical Western understanding of the evolutionary principle through two qualifications that were essentially Chinese in character. First, the 'new citizen' was not an individualized entity of the type located in Western thought but imbued with the Chinese quality of connectedness. The idea of connectedness in this sense was drawn from both the Confucian tradition, in which individuals did not operate in terms of narrowly conceived self-interest but saw their individuality in terms of incontestable moral responsibilities to others, and the Daoist conception of natural interconnectedness of persons through the unavoidable effect on all of the actions of any one person. The 'new citizen', then, while not collective was not an isolated self-sufficient individual, as in Western liberal theory. Whereas western theory is transformed by intellectual entrepreneurs through their introduction of it to a Chinese milieu, in remolding and infusing Western modernism into a Chinese cultural framework, intellectual entrepreneurs reshaped the local context itself. The traditional Chinese notions of interconnectedness and relationality were in this new conceptualization disconnected from the Confucian ideas of filiality in which moral responsibility is principally in familial relations of obligation of son to father and the hierarchies of gender and political relations that parallel kinship roles. In this new and refashioned conception of the moral relations between 
persons, individuals are conceived in their necessary relations not to family members but to the Chinese nation itself.

This loosening of the traditional Chinese conception of the connectedness of individuals from the Confucian idea of filiality or family obligation and loyalty to Emperor and locating it rather in the modernist notion of 'nation' provides the context for the second qualification of the typical Western understanding of the evolutionary principle developed by the new Culture Movement. In this Movement the 'new citizen' was characterized as dynamic, self-assertive and able, qualities which the New Culture Movement saw as the basis of Western power and ability. However, these were qualities conceived by the Movement as not primarily a description of capacities applied to individual persons. Rather, this characterization of the 'new citizen' was intended to be a mobilizing force in creating a new collective Chinese self-image, directed against the conventional stereotype of Chinese passivity and resignation which was not only ascribed to Chinese by unsympathetic foreigners but at this time had come to form an element of the Chinese self-image, reflecting not only China's defeat at the hand of Western powers but the inability of Chinese political leaders, Republican as well as Imperial, to re-assert China's prerogatives in its relations with foreign powers or provide security to Chinese citizens at home.

The New Culture Movement led by intellectual entrepreneurs was therefore neither a movement of wholesale adoption of Western ideas and repudiation of Chinese traditions, nor a movement simply dedicated to preserving Chinese mores and conceptualizations of behaviour and social forms. It was a movement, which as $\mathrm{Yu}$ (2001: 313) observes, promoted 'simultaneously the importation of Western thought and scholarship on the one hand and the "systematic reorganization of national heritage" on the other'. In their employment of Western thought the Chinese intellectual entrepreneurs associated with the New Culture Movement carefully selected concepts and theories they saw as useful to China which they then creatively 
transformed through a synthesis with traditional Chinese categories and approaches, thus assimilating them into existing patterns of Chinese concepts and theories. What has been seen here, though, is that not all Chinese concepts and theories were equally thought to be an appropriate base for the amalgam of ideas that was to form Chinese modernism. In the sinicization of Western ideas there is associated modification of the 'receiving' Chinese framework. In the transformation and incorporation of an alien concept the resulting framework of the local receiving thought is itself adjusted, modified and transformed. The creative reconstitution of old traditions which is the result of the endeavours of intellectual entrepreneurs is continuous with the formation of new combinations which is their primary objective. The emerging new traditions are no less Chinese as the alien concepts incorporated into them are sinicized in the process. It is clear, then, that the work of the intellectual entrepreneurs and the products they provide to others in their milieu cannot be described as mere translations.

\section{Conclusion}

It has been shown through two quite different historical cases that knowledge flow through the diffusion of concepts and theories from one culture or society to another requires the active engagement of a category of agents identified in the discussion as intellectual entrepreneurs. Intellectual entrepreneurs are the key players in this process who initiate, facilitate and carry out conceptual transformation and amalgamation that accompanies and realizes cultural borrowing. Intellectual entrepreneurs do not simply translate or transfer externally sourced ideas into an established context. Rather, they select elements from not one but two contexts, from the body of foreign ideas from which 'useful' notions are appropriated and from the local established traditions into which these ideas or concepts are placed. By combining elements from these two contexts the intellectual entrepreneur makes something quite new that had not previously existed 
and which can operate as a newly introduced knowledge only if the resistance of the established culture has been overcome. In this way knowledge is transferred or diffused from one culture to another. But it is no longer the original knowledge nor is the receiving context unchanged and the same as it was before.

Of all the elements of the intellectual entrepreneur's many connected activities perhaps the least appreciated is their overcoming the resistance the local culture presents to the new amalgam of ideas drawn from a foreign source and melded with familiar notions. Indeed, the concept of resistance is more complex than it first appears and contains a number of different possibilities not all of which are ever realized in any given episode. Resistance can be frictional or purposive, passive or forceful; it can be subversive or conflictual (Barbalet 1985). Discussion in conventional sources gives the impression that there was little or no resistance to the assimilation of Buddhism into China. It is shown above, however, that Mou Tzu primarily addresses opposition to Buddhism rather than simply advocating its virtues. Resistance to Buddhism took many forms: Buddhism was simply ignored when it was first introduced into China but also treated with contempt and disdain when its presence was felt. The Confucian opposition to Buddhism generated a number of polemic texts, especially during the Six dynasties period (222-589), many of them preserved in two compilations, the Collected Essays on Buddhism by Sengyou (Seng-yu) (445-518) and the Further Collection of Essays on Buddhism (Xu gaoseng zhuan) by Daoxuan (596-667) (Fung 1953: 284). The Tang dynasty (618-907) saw an ascendant Buddhism which only encouraged the inventiveness of Confucian resistance. The Neo-Confucian revival of this period incorporated aspects of Buddhist metaphysics and thereby nullifying the Buddhist claims on Chinese thought. There was also careful and insistent Daoist resistance which took subtle forms, unfortunately misunderstood by many scholars. Indeed, the established literature portrays Daoism as simply capitulating to Buddhism, surrendering basic 
tenets and assimilating Buddhist ideas and practices. In a careful analysis of key Daoist texts, the Lingbao Scriptures, Bokenkamp (2010: 204) on the contrary shows that the authors of these scriptures 'rather than "surrendering" to Buddhist ideas, explicitly manipulate them in ways that served to reassert traditional Chinese values' against the original Buddhist notions of 'individual responsibility of karmic predestination'. Indeed, Bokenkamp shows that the assertion of familial responsibility in the Lingbao Scriptures was in turn assimilated into the way Buddhism was practiced in China.

The form and degree of resistance to western ideas in the nineteenth and early twentieth centuries was much more immediate and prevalent than the resistance to Buddhism. The national malaise caused by imported opium from British India, national humiliation generated by defeat in the Opium Wars, and the national burden of debt imposed by foreign encroachment were all felt across China and by all classes. Anti-west sentiment was widely shared and opposition to modern ideas was intensely manifest. Against such resistance the work of modernist intellectual entrepreneurs generated the combustive power that marked the intellectual vigor and challenge of the period. The introduction of foreign ideas into China at this time and their assimilation into the receiving culture was palpably the result of the efforts of dedicated intellectual entrepreneurs, made especially visible through their overcoming the resistance and not simply the inertia of traditional notions and practices.

Any discussion of the assimilation of foreign concepts into a different intellectual culture is required to identify the mechanisms through which concepts are 'diffused' from one context to another. This paper makes a contribution to our understanding of these processes by identifying and examining the role of 'intellectual entrepreneurs' in knowledge transfer. The activities of intellectual entrepreneurs have been examined in order to indicate the processes through which alien concepts and theories are diffused into a receiving culture. It has been shown that foreign 
intellectual sources did not simply pass into Chinese culture and consciousness but rather particular ideas were self consciously selected by intellectual entrepreneurs on the basis of how these ideas might contribute to dealing with problems at both the individual and socio-political levels in China. This general or abstract statement of diffusion has an added political dimension in the case of China from the mid-nineteenth century. The identification of the role of intellectual entrepreneurs and the treatment of the processes they initiate has wide future application in understanding social and cultural change through inter-cultural concept transfer.

\section{Acknowledgments}

I wish to thank the following for their helpful comments on earlier versions of this paper: Professor Jack Barbalet, of Hong Kong Baptist University, Professor Ronald Jacobs and three anonymous reviewers.

\footnotetext{
About the author

Dr Xiaoying Qi is a researcher and lecturer in the School of Humanities and Communication Arts, University of Western Sydney, Australia. Her research interests include conceptual analysis, theory development and cross-cultural comparative analysis. She has published in a number of refereed journals, including the Journal of Sociology, International Sociology and the British Journal of Sociology. Her forthcoming book, Globalized Knowledge Flows and Chinese Social Theory, will appear at the beginning of 2014. Dr Qi is currently researching family obligation in Australia, mainland China and Hong Kong.
} 


\section{Bibliography}

Aronczyk, M. and Craig, A. (2012) Introduction: Culture of Circulation. Poetics 40(2): 93-100.

Barbalet, J. (1985) Power and Resistance. British Journal of Sociology 36(4): 531-548.

Blaut, J. M. (1977) Two Views of Diffusion. Annals of the Association of American Geographers 67(3): 343-349.

Blaut, J. M. (1987) Diffusionism. Annals of the Association of American Geographers 77(1): $30-47$.

Blaut, J. M. (1993) The Colonizer's Model of the World. New York: Guilford Press.

Blue, G. (1999) China and Western Social Thought in the Modern Period. In: T. Brook and G. Blue (eds.) China and Historical Capitalism. Cambridge: Cambridge University Press, pp. 57-109.

Bokenkamp, S. (2010) Imagining Community: Family Values and Morality in the Lingbao Scriptures. In: A. Chan and Y. Lo (eds.) Philosophy and Religion in Early Medieval China. Albany: State University of New York Press, pp. 203-226.

Bourdieu, P. (1999) The Social Conditions of the International Circulation of Ideas. In R. Shusterman (ed.) Bourdieu: A Critical Reader. Oxford: Blackwell Publishers, pp. 220228.

Chabot, S. and Duyvendak, J. (2002) Globalization and Transnational Diffusion between Social Movements. Theory and Society 31(6): 696-740.

Chen, K. (1964) Buddhism in China: A Historical Survey. Princeton: Princeton University Press.

Chen, K. (1973). The Chinese Transformation of Buddhism. Princeton: Princeton University Press. 
Clarke, J. (1997) Oriental Enlightenment: The Encounter between Asian and Western Thought. London: Routledge.

Collins, R. (1998) The Sociology of Philosophies: A Global Theory of Intellectual Change. Cambridge, MA: The Belknap Press of Harvard University Press.

Confucius. (1979) The Analects, translated with an Introduction by D. C. Lau. London: Penguin Books.

Connor, W. (1994) Ethnonationalism: The Quest for Understanding. Princeton, NJ: Princeton University Press.

Cook, F. (1977) Hua-Yen Buddhism. University Park, PA: Pennsylvania State University Press. de Bary, Wm. T. (1959) Some Common Tendencies in Neo-Confucianism. In: D. S. Nivison and A. F. Wright (eds.) Confucianism in Action. Stanford: Stanford University Press, pp. 25-49. de Bary, Wm. T., Chan, W. and Watson, B. (eds.) (1960) Sources of Chinese Tradition, vol. I. New York: Columbia University Press.

Fang, L. (2002) Zhongguo Fojiao Zhexue Yaoyi [The Essence of Chinese Buddhist Philosophy]. Beijing: Chinese People's University Press [in Chinese].

Fine, A. F. (2001) Difficult Reputations. Chicago: University of Chicago Press.

Frickel, S. and Gross, N. (2005) A General Theory of Scientific/Intellecutal Movements. American Sociological Review 2005(70): 204-232.

Fung, E. (2010). The Intellectual Foundations of Chinese Modernity. Cambridge: Cambridge University Press.

Fung, Y. (1953) A History of Chinese Philosophy, vol. II. Princeton: Princeton University Press. Furth, C. (2002) Intellectual Change. In: M. Goldman and L. Lee (eds.) An Intellectual History of Modern China. Cambridge: Cambridge University Press, pp. 13-96.

Goody, J. (1996) The East in the West. Cambridge: Cambridge University Press. 
Goody, J. (2004) Capitalism and Modernity. Cambridge: Polity Press.

Gouldner, A. (1979) The Future of the Intellectuals and the Rise of the New Class. New York: Oxford University Press.

Hannerz, U. (1990) Cosmopolitans and Locals in World Culture. Theory, Culture and Society, 7(2): $237-251$.

Holton, R. (2005) Making Globalisation. London: Palgrave MacMillan.

Hsu, C. (2001) Chinese Encounters with Other Cultures. International Sociology 16(3):438-454.

Huang, S. (1999) Essentials of Neo-Confucianism. Westport: Greenwood Press.

Inkeles A. and Sirowy, L. (1983) Convergent and Divergent Trends in National Educational Systems. Socical Forces 62: 303-333.

Kang, Y. (1958) Ta T’ung Shu. Thompson. London: George Allen \& Unwin Ltd.

Kaufman, J. and Patterson, O. (2005) Cross-National Cultural Diffusion: The Global Spread of Cricket. American Sociological Review 70: 82-110.

Keenan, J. (1994) How Master Mou Removes our Doubts. Albany: State University of New York Press.

Kroeber, A. (1940) Stimulus Diffusion. American Anthropologist 42(1): 1-20.

Kuhn, Thomas S. (1970). The Structure of Scientific Revolutions. Second enlarged edition. Chicago, IL: University of Chicago Press.

Lai, K. (2008) An Introduction to Chinese Philosophy. Cambridge: Cambridge University Press.

Lee, B. and LiPuma, E. (2002) Culture of Circulation: The Imaginations of Modernity. Public Culture 14(1): 191-213.

Lin, Y. (1979) The Crisis of Chinese Consciousness. London: The University of Wisconsin Press. Locke, J. (1963) Two Treatises of Government, edited by P. Laslett. New York: New American Library. 
Lusthaus, D. (1998) Buddhist Philosophy, Chinese. In: E. Craig (ed.) Routledge Encyclopaedia of Philosophy. London: Routledge. http://www.rep.routledge.com/article/G002SECT1, retrieved 6 April 2011.

McAdam, D., Tarrow, S. and Tilly, C. (2001) Dynamics of Contention. Cambridge: Cambridge University Press.

Mclaughlin, N. (2001) Optimal Marginality: Innovation and Orthodoxy in Fromm's Revision of Psychoanalysis. Sociological Quarterly 42(2): 271-288.

McNeill, W. (1988) 'Diffusion in History'. In: P. Hugill and D. Dickson (eds.) The Transfer and Transformation of Ideas and Material Culture. College Station: Texas A\&M University Press, Pp. 75-90.

Mencius. (2004) Mencius, translated with an Introduction and Notes by D. C. Lau. London: Penguin.

Mou, Tzu. (1994) 'Li-huo Lun'. In J. Keenan (ed.) How Master Mou Removes our Doubts. Albany: State University of New York Press, pp. 47-176.

Needham, J. (1956). Science and Civilization in China, vol. 2. Cambridge: Cambridge University Press.

Pusey, J. (1983). China and Charles Darwin. Cambridge, MA: Council on East Asian Studies.

Qi, X. (2014) Globalized Knowledge Flows and Chinese Social Theory. London and New York: Routledge. Forthcoming.

Rogers, E. M. (1995) Diffusion of Innovations. New York: Free.

Schumpeter, J. (2008) The Theory of Economic Development. New Brunswick: Transaction Publishers.

Schwartz, B. (1969) In Search of Wealth and Power: Yen Fu and the West, with an Introduction by Louis Hartz. New York: Harper \& Row. 
Schwartz, B. (1985) China's Cultural Values. Tempe, Arizona: Centre for Asian Studies, Arizona State University.

Schwartz, B. (2002) Themes in Intellectual History. In: M. Goldman and L. Lee (eds.) An Intellectual History of Modern China'. Cambridge: Cambridge University Press, pp. 97141.

Shen, F. (1996) Cultural Flow between China and the Outside World Throughout History. Beijing: Foreign Languages Press.

Spence, J. (1999) In Search for Modern China. New York: W. W. Norton \& Company.

Stark, D. (1991) Path Dependence and Privatization Strategies in East Central Europe. East European Politics and Societies 6: 17-54.

Strang, D. and Meyer, J. W. (1993) Institutional Conditions for Diffusion. Theory and Society 22: 487-511.

Swanson, P. (1995) Foundations of T'Ien-T'Ai Philosophy. Berkeley, CA: Asian Humanities Press.

Tillman, H. (1990) Yan Fu's Utilitarianism in Chinese Perspective. In: P. Cohen and M. Goldman (eds.) Ideas Across Cultures: Essays on Chinese Thought in Honour of Benjamin I. Schwartz. Cambridge, MA: Council on East Asian Studies, pp. 63-84.

Tsukamoto, Z. (1985) A History of Early Chinese Buddhism: From its Introduction to the Death of Hui-yuan, translated by L. Hurvitz. Kokyo: Kodansha.

Weber, M. (1964) The Religion of China. New York: The Free Press.

Wejnert, B. (2002) Integrating Models of Diffusion of Innovations: A Conceptual Framework. Annual Review of Sociology 28: 297-326.

Wong, Y. (2010) Beyond Confucian China: The Rival Discourse of Kang Youwei and Zhang Binglin. Routledge: London and New York. 
Wright, A. (1959) Buddhism in Chinese History. Stanford: Stanford University Press.

Wright, A. (1990) Studies in Chinese Buddhism. New Haven and London: Yale University Press.

Yu, Y. (2001) Neither Renaissance nor Enlightenment. In: M. Dolezelova-Velingerova and O. Kral (eds.) The Appropriation of Cultural Capital: China's May Fourth Project. Cambridge: Harvard University Press, pp. 299-320.

Zürcher, E. (2007). The Buddhist Conquest of China. Leiden : Brill. 